JAMP: Jurnal Adminitrasi dan Manajemen Pendidikan

Volume 4 Nomor 4 Desember 2021, Hal : 300 - 306

Tersedia Online di http://journal2.um.ac.id/index.php/jamp/

ISSN 2615-8574 (online)

\title{
MENILAI KESIAPAN PROGRAM STUDI MENGHADAPI AKREDITASI SEMBILAN KRITERIA MELALUI ANALISIS SWOT
}

\author{
Slamet Riyanto, Muh Nur Luthfi Azis \\ Universitas PGRI Madiun \\ Jl. Setia Budi No.85, Kanigoro, Madiun \\ Email: 1selamat@unipma.ac.id
}

\begin{abstract}
This study aims to determine the readiness of the Informatics Engineering study program in facing the accreditation of nine criteria through a SWOT analysis. This study uses a SWOT analysis approach by calculating the weight, rating and score of the respondents' assessment questionnaire. The results show that the Informatics Engineering study program has a position in quadrant two and the right strategy is to apply a grand stability strategy with a turn around strategy approach. The Informatics Engineering study program must make fundamental changes to improve the ability to face nine criteria accreditation and increase the reputation or selling value of the Informatics Engineering study program to the wider community.
\end{abstract}

Keywords: SWOT; Stability Strategy; Accreditation

\begin{abstract}
Abstrak: Penelitian ini bertujuan untuk mengetahui kesiapan program studi Teknik Informatika dalam menghadapi akreditasi sembilan kriteria melalui analisis SWOT. Penelitian ini menggunakan pendekatan analisis SWOT dengan melakukan perhitungan terhadap bobot, rating dan skor dari hasil kuesioner penilaian responden. Hasil penelitian menunjukkan bahwa program studi Teknik Informatika memiliki posisi di kuadran dua dan strategi yang tepat adalah menerapkan grand strategy stability dengan pendekatan strategi turn around. Program studi Teknik Informatika harus melakukan perubahan secara mendasar untuk meningkatkan kemampuan dalam menghadapi akreditasi sembilan kriteria serta meningkatkan reputasi atau nilai jual program studi Teknik Informatika kepada masyarakat luas.
\end{abstract}

Kata kunci: SWOT; Strategi Stability; Akreditasi

peningkatan kualitas pendidikan dari lembaga pendidikan banyak dilakukan tanpa melalui analisis yang komprehensif, sehingga banyak lembaga pendidikan yang memiliki kinerja kurang baik (Kadri \& Widiawati, 2020). Kinerja lembaga pendidikan yang kurang baik akan berdampak pada komponen lembaga pendidikan dan dapat menyebabkan tekanan psikologis bagi pegawai, siswa/mahasiswa maupun orangtua yang mempercayakan pendidikan anak kepada lembaga tersebut (Anshory, 2018) various children with disabilities require different guidance and assistance in terms of curriculum, lesson plans, media, and assessment (Weaknesses.

Tekanan psikologis pernah dialami oleh program studi Teknik Informatika Universitas PGRI Madiun (UNIPMA) yang saat itu dari tahun 1996-2019 masih terakreditasi C. Belajar dari pengalaman tata kelola yang kurang baik serta tidak adanya strategi pengembangan yang dijalankan, maka sejak tahun 2017 komponen program studi bekerja keras untuk memperbaiki tata kelola dan mulai menyusun strategi untuk keluar dari tekanan psikologis ini. Al hasil, pada tahun 2020 program studi mendapat akreditasi B dan menjadi salah satu program studi favorit di UNIPMA. Kesempatan ini terus dimanfaatkan dengan melakukan tata kelola yang dengan baik dan dilakukan perencanaan strategi yang tepat untuk mencapai visi, misi dan tujuan yang telah ditetapkan. 
Strategi pengembangan program studi Teknik Informatika dirancang dengan mempertimbangan empat aspek, yaitu input, proses, output dan outcome. Keempat aspek ini memegang peran penting terkait dengan keberlangsungan program studi dalam menghadapi tantangan regulasi pendidikan dan perkembangan teknologi, khususnya terkait dengan persiapan akreditasi sembilan kriteria. Program studi diharapkan mampu mengidentifikasi faktor eksternal dan internal yang mempengaruhi perkembangan program studi melalui analisis SWOT (Strenghts, Weakness, Opportunities and Threats).

Strategi pengembangan instansi pendidikan telah banyak dilakukan oleh perguruan tinggi dengan tujuan untuk mengetahui posisi dan strategi yang akan dijalankan, sehingga perguruan tinggi dapat tetap eksis dalam menghadapi perubahan jaman. Analisis SWOT dalam dunia pendidikan dapat diterapkan untuk menentukan strategi pelaksanaan pendidikan secara keseluruhan (Chen, 2014). Analisis SWOT ini juga berperan dalam menentukan pertumbuhan organisasi (Devi, 2018). Analisis SWOT juga penting dalam penyesuaian kurikulum yang digunakan lembaga pendidikan agar lulusan mudah diterima penggunanya (Moeini et al., 2016), dengan demikian dapat dilakukan pemetaan kurikulum yang kolaboratif dengan dunia kerja (Kamrozzaman et al., 2018).

Banyak strategi yang dihasilkan dari analisis SWOT yang didasarkan pada data yang dikumpulkan, misalnya universitas dapat menerapkan strategi pertumbuhan stabilisasi, yaitu tumbuh sesuai dengan kemampuan yang dimiliki dengan cara bertahap (Nofrizal \& Soviyanti, 2018). Analisa SWOT digunakan untuk pilihan strategi dalam memahami potensi Perguruan Tinggi Swasta (PTS) untuk tetap survive. PTS diharapkan memperhatikan mutu dosen dan kinerja tenaga kependidikan untuk meningkatkan daya saing perguruan tinggi serta meningkatkan daya saing lulusan perguruan tinggi (Resmi \& Mekarsari, 2017). Perencanaan strategi dengan menggunakan menganalisis SWOT dan Balance Scorecard (BSC) yang memiliki empat perspektif yang meliputi keuangan, pelanggan, proses bisnis internal, serta pembelajaran dan pertumbuhan (Retnawati, 2018)e-learning, financial system, staffing system, e-Slip and various other applications that are not fully integrated yet. The many systems and applications are an asset to XYZ University's institutions, because in its development it has taken quite a bit of time and resources. Therefore, the institution must fully utilize to support the institution in accelerating the achievement of the vision and mission that has been set so that the application of ICT be aligned with the business interests of the institution of Wijaya Kusuma University Surabaya. Then the institution must prepare a strategic information system / information technology (SI / IT

Lembaga pendidikan dapat mengembangkan strategi untuk mengatasi ancaman eksternal dan mengambil peluang yang ada. Perencanaan strategis adalah proses menganalisis, merumuskan dan mengevaluasi strategi yang telah dilakukan sebelumnya. Tujuan utama perencanaan strategis adalah untuk melihat secara objektif kondisi-kondisi internal dan eksternal, sehingga organisasi dapat mengantisipasi perubahan lingkungan eksternal (Rangkuti, 2018). Strategi adalah alat yang sangat penting untuk mencapai keunggulan bersaing. Keunggulan bersaing akan didapat oleh organisasi apabila memiliki kekuatan yang tidak mudah ditiru oleh organisasi pesaing. Terdapat dua faktor yang menentukan organisasi memiliki kemampuan spesifik yang mendukung keunggulan bersaing, yaitu: keahlian tenaga kerja dan kemampuan sumber daya. Dua faktor ini menyebabkan organisasi tersebut dapat lebih unggul dibandingkan dengan pesaingnya.

Secara spesifik, analisis SWOT sebagai alat analisis yang digunakan dalam suatu perusahaan untuk menemukan strategi yang paling tepat agar perusahaan dapat mencapai tujuannya (Keban et al., 2019), juga dapat digunakan untuk memetakan posisi program studi dalam menghadapi akreditasi sembilan kriteria yang dianggap sangat memberatkan program studi. Analisis SWOT ini akan mengidentifikasi berbagai faktor secara sistematis untuk merumuskan strategi program studi. Analisis ini didasarkan pada logika yang dapat memaksimalkan kekuatan dan peluang, namun secara bersamaan dapat meminimalisasi kelemahan dan ancaman. Proses pengambilan keputusan strategis selalu berkaitan dengan pengembangan misi, tujuan, strategi dan kebijakan organisasi (Rangkuti, 2018). Analisis SWOT juga relevan untuk dijadikan sebagai analisis penilaian informasi dalam menentukan kebijakan strategi bagi organisasi (Saienko \& Lavrysh, 2020)weaknesses, opportunities, and threats (SWOT. Hasil analisis SWOT di dunia pendidikan juga mampu menjadi bahan strategi untuk memperkuat karakter pendidikan 
dan melakukan transformasi pendidikan yang dilakukan lembaga pendidikan (Satria \& Shahbana, 2020; Solihin et al., 2019).

Pemanfaatan analisis SWOT juga mengarah pada kegiatan manajemen pendidikan yang lebih terarah. Manajemen pendidikan adalah proses mengelola upaya kolaboratif oleh sekelompok orang yang tergabung dalam suatu organisasi pendidikan. Tujuannya untuk mencapai tujuan pendidikan yang telah ditentukan dengan memanfaatkan sumber daya yang ada dan menggunakan fungsi manajemen secara efektif dan efisien (Keban et al., 2019). Manajemen pendidikan ini yang akan menentukan tata kelola yang baik dalam mencapai visi, misi dan tujuan yang telah dirumuskan.

Terkait dengan penelitian ini, peneliti menggunakan pendekatan analisis SWOT dengan melibatkan pihak internal (dosen dan mahasiswa) dan eksternal (pengguna lulusan atau mitra industri) dalam penilaian SWOT yang digunakan. Hal ini berbeda dengan penelitian sebelumnya yang kebanyakan hanya menggunakan pihak internal saja dalam penilaian SWOT. Hasil penelitian ini juga mampu memberikan informasi terkait dengan posisi kuadran dari objek penelitian serta bagaimana strategi yang akan diterapkan berdasarkan faktor internal dan eksternal yang ada. Dengan demikian, tujuan penelitian untuk mengetahui kesiapan program studi Teknik Informatika dalam menghadapi akreditasi sembilan kriteria melalui analisis SWOT, dapat dijawab secara tepat berdasarkan data yang dikumpulkan.

\section{METODE}

Jenis penelitian ini adalah penelitian kuantitatif dengan menggunakan data kuesioner terkait dengan SWOT (Kumorowati et al., 2020). Studi kasus dilakukan pada program studi Teknik Informatika pada tahun akademik 2020/2021. Penelitian ini menggunakan pendekatan analisis SWOT dengan melakukan analisis terhadap bobot, rating dan skor dari hasil kuesioner penilaian responden yang terdiri dari, dosen, mahasiswa dan pengguna lulusan. Skala penilaian yang digunakan untuk penilaian kondisi saat ini dengan skala $1=$ sangat kurang sampai $4=$ sangat baik dan penilaian urgensi penanganan dengan skala $1=$ tidak penting sampai 4 = sangat penting (Tambunan, 2020). Analisis SWOT akan dilakukan secara periodik sehingga diperoleh kumpulan data dari waktu ke waktu untuk menjadi big data. Di era big data dapat dimanfaatkan analisis kerangka kekuatan, kelemahan, peluang, dan ancaman (SWOT) yang dimiliki program studi (Ahmadi et al., 2016).

\section{HASIL}

Hasil pengolahan data dari penyebaran kuesioner untuk perhitungan faktor internal yang meliputi kekuatan dan kelemahan disajikan pada Tabel 1.

Tabel 1 Perhitungan Bobot dan Skor untuk Faktor Internal

\begin{tabular}{lccc}
\hline \multicolumn{1}{c}{ Faktor Internal } & Bobot & Rating & Skor \\
\hline Kekuatan & & & \\
Akreditasi B Perguruan Tinggi & 0,057 & 3,71 & 0,21 \\
Akreditasi B Program Studi & 0,058 & 3,64 & 0,21 \\
Kegiatan pembelajaran daring & 0,053 & 3,64 & 0,19 \\
Kerjasama prodi dengan dunia usaha dan dunia industri (DUDI) & 0,052 & 3,57 & 0,19 \\
Kerjasama prodi dengan (NGO)/LSM & 0,046 & 3,14 & 0,15 \\
Prodi melaksanakan program Merdeka Belajar & 0,052 & 3,43 & 0,18 \\
Mahasiswa mengikuti program Merdeka Belajar & 0,055 & 3,43 & 0,19 \\
Inovasi produk hasil penelitian dosen dan mahasiswa & 0,055 & 3,57 & 0,19 \\
Lulusan yang memperoleh pekerjaan dalam waktu 6 bulan & 0,060 & 3,43 & 0,21 \\
Total & 0,488 & & 1,72
\end{tabular}




\begin{tabular}{llll}
\hline \multicolumn{1}{c}{ Faktor Internal } & Bobot & Rating & Skor \\
\hline Kelemahan & Bobot & Rating & Skor \\
Jumlah dosen yang studi lanjut S3 & 0,029 & 3,64 & 0,11 \\
Jumlah dosen jabatan Lektor dan Lektor Kepala & 0,029 & 3,79 & 0,11 \\
Rasio jumlah mahasiswa terhadap dosen & 0,046 & 3,50 & 0,16 \\
Kemampuan dosen untuk menjadi praktisi di DUDI & 0,045 & 3,36 & 0,15 \\
Jumlah artikel ilmiah terindeks per dosen & 0,049 & 3,36 & 0,16 \\
Kinerja penelitian dosen & 0,052 & 3,29 & 0,17 \\
Kinerja pengabdian masyarakat oleh dosen & 0,053 & 3,21 & 0,17 \\
Prestasi mahasiswa di tingkat nasional & 0,052 & 3,43 & 0,18 \\
Dosen yang memiliki sertifikat nasional / internasional & 0,048 & 3,50 & 0,17 \\
Jumlah sitasi per dosen & 0,052 & 3,43 & 0,18 \\
Jumlah HAKI /paten per dosen & 0,056 & 3,36 & 0,19 \\
$\quad$ Total & 0,512 & & 1,75 \\
\multicolumn{1}{c}{ S-W } & 1,000 & & $-0,03$ \\
\hline
\end{tabular}

Perhitungan faktor eksternal yang meliputi peluang dan aancaman disajikan pada Tabel 2 berikut:

Tabel 2. Perhitungan Bobot dan Skor untuk Faktor Eksternal

\begin{tabular}{|c|c|c|c|}
\hline Faktor Ekternal & Bobot & Rating & Skor \\
\hline \multicolumn{4}{|l|}{ Peluang } \\
\hline Keberadaan mahasiswa asing & 0,048 & 3,21 & 0,15 \\
\hline Program pertukaran mahasiswa dari Dikti & 0,079 & 3,36 & 0,26 \\
\hline Animo masyarakat terhadap prodi informatika & 0,112 & 3,64 & 0,41 \\
\hline Biaya kuliah yang kompetitif & 0,103 & 3,29 & 0,34 \\
\hline Biaya hidup mahasiswa yang terjangkau & 0,103 & 3,07 & 0,32 \\
\hline Lingkungan masyarakat kampus yang mendukung & 0,105 & 3,14 & 0,33 \\
\hline Keberadaan dunia usaha dan dunia industri di wilayah Madiun & 0,103 & 3,57 & 0,37 \\
\hline Total & 0,652 & & 2,18 \\
\hline \multicolumn{4}{|l|}{ Ancaman } \\
\hline Persiapan prodi terhadap penerapan akreditasi 9 kriteria & 0,081 & 3,71 & 0,30 \\
\hline Kolaborasi prodi dengan Perguruan Tinggi Negeri di Karesidenan Madiun & 0,083 & 3,64 & 0,30 \\
\hline Kesiapan prodi terhadap pandemi Covid 19 & 0,101 & 3,64 & 0,37 \\
\hline Peraturan sertifikat tenaga kerja & 0,083 & 3,43 & 0,29 \\
\hline Total & 0,348 & & 1,26 \\
\hline $\mathrm{O}-\mathrm{T}$ & 1,000 & & 0,92 \\
\hline
\end{tabular}

Berdasarkan Tabel 1 dan Tabel 2 untuk perhitungan bobot dan skor analisis SWOT, maka dapat dibuat diagram untuk mengetahui posisi program studi seperti Gambar 1. Berdasarkan Gambar 1, menunjukkan bahwa program studi Teknik Informatika memiliki positioning pada kuadran 2 dengan grand strategy stability yang mengarah pada opportunities dengan sedikit kelemahan. Grand strategy stability menggunakan pendekatan strategi turn around. Turn around merupakan strategi yang digunakan seorang pemimpin untuk melakukan perubahan yang banyak menghadapi kendala. Kendala yang dihadapi masih memiliki banyak waktu untuk dicari solusi pemecahannya. Turn around dapat diartikan sebagai strategi untuk membuang yang jelek-jelek dengan melakukan perubahan yang mendasar. 


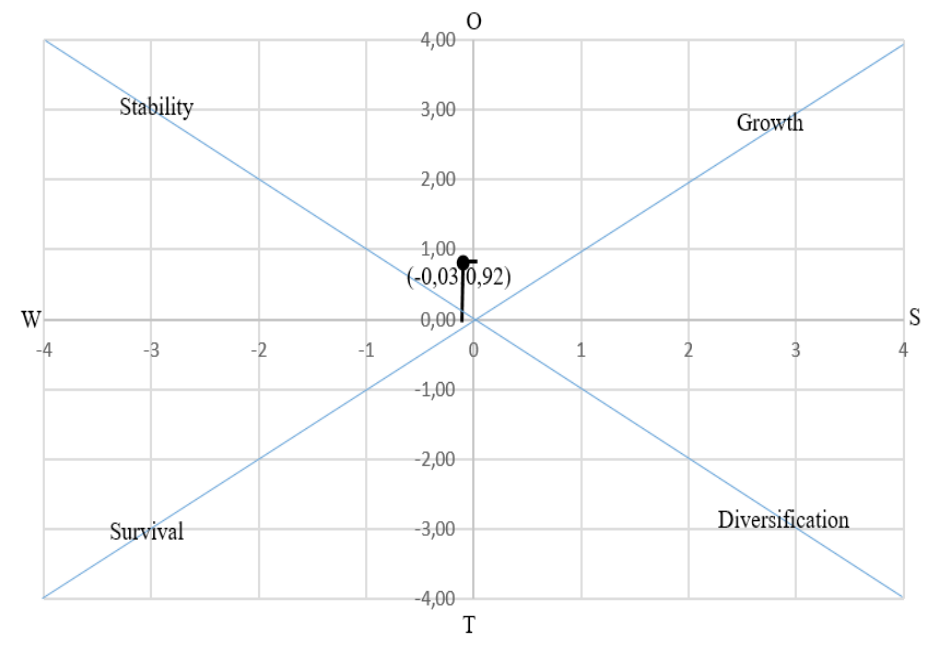

Gambar 1. Diagram Analisis SWOT

\section{PEMBAHASAN}

Strategi turn around ini sesuai dengan kondisi program studi dalam menghadapi akreditasi sembilan kriteria, dimana program studi Teknik Informatika harus melakukan perubahan-perubahan yang mendasar terutama terkait dengan kepemimpinan kepala program studi, pengelolaan manajemen program studi, sistem operasional program studi harus lebih banyak melakukan pendekatan kepada stakeholder sehingga nilai dari program studi dapat meningkat. Strategi terkait dengan kepemimpinan kepala program studi yang dapat dilakukan adalah: 1. Mewajibkan dosen untuk melakukan kegiatan penelitian dan pengabdian kepada masyarakat dengan luaran publikasi pada jurnal nasional atau internasional terakreditasi serta publikasi di media massa; 2 . Menerapkan kurikulum merdeka belajar secara konsisten; 3. Membuka program pertukaran mahasiswa asing dan meningkatkan kegiatan magang di luar negeri; 4. Memonitoring dan mengevaluasi jabatan akademik dosen secara periodik; 5 . Mendorong dosen untuk segera melakukan studi lanjut S3.

Strategi pengelolaan manajemen program studi dalam menghadapi akreditasi sembilan kriteria, maka perlu dipersiapkan antara lain: 1. Mengembangkan model dan metode pembelajaran daring yang efektif dan efisien; 2. Melibatkan semua unsur program studi dalam pengembangan program studi; 3. Memperbanyak kegiatan workshop dan pelatihan yang beersertifikat bagi dosen dan mahasiswa; 4 . Meningkatkan pelayanan akademik dan non akademik untuk meningkatkan prestasi mahasiswa di level nasional; 5. Memperbaiki sarana dan prasarana yang menunjang kegiatan belajar dan mengajar.

Strategi untuk sistem operasional program studi harus lebih banyak melakukan pendekatan kepada stakeholder, maka langkah program studi adalah: 1. Meningkatkan kualitas kerjasama dengan dunia usaha dan dunia industri (DUDI) dalam kegiatan magang industri melalui kegiatan Merdeka Belajar Kampus Merdeka; 2. Menjalin hubungan dengan Sekolah Menengah Kejuruan dan Sekolah Menengah Atas untuk menjaring calon mahasiswa yang berkualitas serta lulusan yang berkualitas; 3 . Meningkatkan keterlibatan dosen dalam DUDI; 4. Merekrut praktisi di DUDI sebagai dosen tetap dengan perjanjian kerja dan memiliki Nomor Induk Dosen Khusus (NIDK).

Strategi turn around juga bisa didukung dengan strategi komunikasi proaktif dan strategi isolasi dengan strategi promosi pemasaran yang efektif merupakan strategi terbaik yang dapat diterapkan guna mempertahankan kepercayaan stakeholder selama ini (Oreski, 2012). Perbaikan program kerja perlu dilakukan guna menyesuaikan strategi yang dihasilkan dari analisis SWOT (Orr, 2012).

Hasil penelitian ini juga relevan dengan penelitian yang terdahulu yang menyatakan bahwa analisis SWOT digunakan untuk mengamati atau melakukan penelitian dengan memperhatikan faktor internal dan eksternal yang ada dalam suatu lembaga pendidikan (Limbong, 2019). Analisis SWOT juga 
digunakan sebagai analisis adaptasi pendidikan di Amerika dan Irlandia pada masa pandemi covid-19 (Longhurst et al., 2020)necessitated by social distancing measures preventing face-to-face teaching. This has led to an almost immediate switch to distance learning by higher education institutions. Anatomy faces some unique challenges. Intrinsically, anatomy is a three-dimensional subject that requires a sound understanding of the relationships between structures, often achieved by the study of human cadaveric material, models, and virtual resources. This study sought to identify the approaches taken in the United Kingdom and Republic of Ireland to deliver anatomical education through online means. Data were collected from 14 different universities in the United Kingdom and Republic of Ireland and compared adopting a thematic analysis approach. Once themes were generated, they were collectively brought together using a strength, weakness, opportunity, threat (SWOT.

Pada penelitian terdahulu juga ditemukan bahwa identifikasi dari kekuatan, kelemahan, peluang dan ancaman dalam pendidikan tinggi yang dihadapi akan menjadi acuan bagi pembuat kebijakan dapat mengembangkan rencana / strategi untuk memperbaiki sistem pembelajaran (Nasreen \& Afzal, 2020). Strategi yang diperoleh dari hasil analisis SWOT merupakan tindakan untuk mengatasi kelemahan dan acaman secara efektif dan memanfaatkan kekuatan dan peluang yang dimiliki (Yigit et al., 2014) Weaknesses, Opportunities, and Threats (SWOT.

\section{SIMPULAN}

Program studi Teknik Informatika berada pada kuadran 2 dengan grand strategy stability dan mengarah pada faktor opportunities serta sedikit faktor kelemahan. Grand strategy stability ini menggunakan pendekatan strategi turn around, dimana program studi harus melakukan strategi perubahan secara mendasar untuk persiapan akreditasi sembilan kriteria. Strategi perubahan yang mendasar meliputi kepemimpinan kepala program studi, pengelolaan manajemen program studi, sistem operasional program studi harus lebih banyak melakukan pendekatan kepada stakeholder sehingga nilai dari program studi dapat meningkat.

\section{DAFTAR RUJUKAN}

Ahmadi, M., Dileepan, P., \& Wheatley, K. K. (2016). A SWOT analysis of big data. Journal of Education for Business, 91(5), 289-294. https://doi.org/10.1080/08832323.2016.1181045

Anshory, I. (2018). SWOT Analysis on Inclusive Education in Indonesia. Advances in Social Science, Education and Humanities Research, 231(Amca), 255-258. https://doi.org/10.2991/amca-18.2018.70

Chen, M. (2014). SWOT analysis and strategies to support college physical education through distance education. World Transactions on Engineering and Technology Education, 12 (4), 671-674.

Devi, U. N. (2018). A SWOT Analysis Of Cross Border Higher Education in India. IGNASA International Journal of Commerce \& Management, January, 63-72.

Kadri, H. AL, \& Widiawati. (2020). Strategic Planning in Developing the Quality of Educators and Education Personnel. Indonesian Research Journal in Education, 4(2), 324-346.

Kamrozzaman, N. A., Badusah, J., \& Mohammad, W. M. R. W. (2018). Coggle: SWOT Analysis in Lifelong Learning Education Using Online Collaborative Mind-Mapping. International Journal of Academic Research in Business and Social Sciences, 8(12), 2195-2206. https://doi.org/10.6007/ijarbss/v8-i12/5431

Keban, Y. B., Arifin, S., \& Wahyono, R. (2019). SWOT Analysis and Its Implementation Strategies in Educational Management. Journal of Education and Practice, 10(12), 86-92. https://doi.org/10.7176/jep/10-12-10

Kumorowati, B., Sarwi, S., Sutikno, S., \& Rahman, F. A. (2020). SWOT Analysis of the Appropriate Profile of the Prospective Ship Officer Cognitive Abilities in Understanding the Essence Concept of Sea Water Mechanics with the Challenges of the Industrial Era 4 . 0. Journal of Curriculum Indonesia, 3(1), 16-29.

Limbong, M. (2019). SWOT analysis in improving the quality of basic education at palm plantation in Indonesia. Journal of Physics: Conference Series, 1360(1), 1-7. https://doi.org/10.1088/1742-6596/1360/1/012030

Longhurst, G. J., Stone, D. M., Dulohery, K., Scully, D., Campbell, T., \& Smith, C. F. (2020). Strength, Weakness, Opportunity, Threat (SWOT) Analysis of the Adaptations to Anatomical Education in the United Kingdom and Republic of Ireland in Response to the Covid-19 Pandemic. Anatomical Sciences Education, 13(3), 301311. https://doi.org/10.1002/ase.1967 
Moeini, S., Moradian, N., \& Khoroshi, P. (2016). Developing Multi-grade Classes using SWOT Analysis. Mediterranean Journal of Social Sciences, 7(4), 197-202. https://doi.org/10.5901/mjss.2016.v7n4s2p197

Nasreen, K., \& Afzal, M. T. (2020). Strengths, weaknesses, opportunities and threats in higher education: a SWOT analysis of Allama Iqbal Open University Islamabad (Pakistan). Asian Association of Open Universities Journal, 15(3), 321-333. https://doi.org/10.1108/aaouj-11-2019-0052

Nofrizal, \& Soviyanti, E. (2018). Analisis Swot Untuk Menentukan Posisi Strategis Pada Universitas Lancang Kuning Pekanbaru. Economica, 7(1), 97-116. https://doi.org/10.22202/economica.2018.v7.i1.2637

Oreski, D. (2012). Strategy development by using SWOT-AHP. TEM Journal, 1(4), 283-291.

Orr, B. (2012). Conducting a S.W.O.T. Analysis for Program Improvement. US-China Education Review A, 3(6), 381-384. https://doi.org/10.5176/2251-1814_eel12.18

Porter, E. M. (1985). Competitive Advantage-Creating and Sustaining. Superior Performance.

Rangkuti, F. (2018). Teknik Membedah Kasus Bisnis, Analisis SWOT. PT. Gramedia Pustaka Utama.

Resmi, N. N., \& Mekarsari, N. K. A. (2017). Pengembangan Perguruan Tinggi Swasta melalui Analisis SWOT. Prosiding Seminar : Revitalisasi Tata Kelola Perguruan Tinggi Juni 2017, 14, 178-191. fisip-unipas.com/ asset/user_file/20171126023321_ni nyoman resmi \& ni ketut adi mekarsari- prosiding revitalisasi tata kelola perguruan tinggi 2017.pdf

Retnawati, L. (2018). Perencanaan Strategis SI/Ti Dengan Metode Analisa SWOT Dan BSC Untuk Meningkatkan Daya Saing Di Universitas Xyz. JISKA (Jurnal Informatika Sunan Kalijaga), 2(3), 135-142. https://doi. org/10.14421/jiska.2018.23-02

Saienko, N., \& Lavrysh, Y. (2020). Mobile assisted learning for self-directed learning development at technical university: SWOT analysis. Universal Journal of Educational Research, 8(4), 1466-1474. https://doi. org/10.13189/ujer.2020.080440

Satria, R., \& Shahbana, E. B. (2020). The SWOT Analysis of Strengthening Character Education In Junior High School. Jurnal Iqra': Kajian Ilmu Pendidikan, 5(2), 56-67. https://doi.org/10.25217/ji.v5i2.827

Solihin, M., Jalaludin, J., Novita, M., \& Ismail, M. S. (2019). SWOT Analysis on The Transformation of Islamic Higher Education. Jurnal Pendidikan Islam, 5(2), 159-174. https://doi.org/10.15575/jpi.v5i2.3107

Tambunan, T. S. (2020). SWOT Analysis for Tourism Development Strategy of Samosir Regency. TIJAB (The International Journal of Applied Business), 4(2), 90-105. https://doi.org/10.20473/tijab.v4.i2.2020.90-105

Yigit, A. S., Al-Ansary, M. D., \& Al-Najem, N. M. (2014). Swot Analysis and Strategic Planning As an Effective Tool for Improving Engineering Education At Kuwait University. October 2003, 1-8. 